\title{
Juventude, radioescola e cidadania: apontamentos teórico-metodológicos
}

\author{
Tarciana Campos \\ Mestra em Comunicação e jornalista da ONG Catavento Comunicação e Educação. \\ E-mail: tarcianacampos@hotmail.com \\ Alexandre Barbalho \\ Doutor em Comunicação e Cultura Contemporâneas pela UFBA. Professor dos PPGs em \\ Políticas Públicas da UECE e em Comunicação da UFC. \\ E-mail: alexandrealmeidabarbalho@gmail.com
}

Resumo: Este artigo traz o percurso metodológico empreendido em uma pesquisa sobre a atuação cidadã em radioescola por parte de jovens estudantes do Ensino Fundamental na rede pública municipal de Fortaleza. O objetivo central da pesquisa foi analisar as experiências e práticas juvenis nos processos de produção, circulação de conteúdos e gestão de radioescolas. $\bigcirc$ trabalho de campo, por sua vez, centrou-se em quatro escolas públicas que participaram do programa Antenados, desenvolvido pela ONG Catavento Comunicação e Educação.

Palavras-chave: Juventude, radioescola, cidadania, metodologia, educação.
Abstract: This article discuss the methodology of a research on the role of citizenship in radio schools conducted by young elementary school students in the public system of education of Fortaleza. The main objective was to analyze the experiences and practices in juvenile processes of production, circulation and content management in radio schools. The fieldwork focused on four schools that participated in the program developed Antenados by the NGO named Catavento Communication and Education.

Keywords: Youth; Radio school; Citizenship; Methodology; Education.

Os estudos e pesquisas sobre comunicação e cidadania têm alcançado lugar relevante na produção acadêmica brasileira. Um dos sinais mais visíveis desse fenômeno é a existência de grupos ligados ao tema dentro dos dois principais eventos científicos da área da comunicação (os simpósios nacionais da Intercom - Sociedade Brasileira de Estudos Interdisciplinares da Comunicação - e os encontros anuais da Compós - Associação Nacional dos Programas de Pós-Graduação em Comunicação).

No caso específico do grupo da Intercom, que já possui dez anos de atividades, constata-se que os trabalhos são, em sua maioria, estudos de caso, sendo outros poucos ligados à discussão teórico-metodológica ${ }^{1}$. Contudo, esse é um debate fundamental no acompanhamento da constante transformação que o conceito de cidadania vem atravessando, em grande parte ocasionada 
comunicação \& educação • Ano XVII • número 2 • jul/dez 2012

pelos processos de mediatização - o que exige do pesquisador, inclusive, uma perspectiva inter ou até mesmo transdisciplinar, bem como o compromisso com seus sujeitos interlocutores ${ }^{2}$.

Partindo desse pressuposto, trazemos o percurso metodológico empreendido por uma pesquisa voltada à atuação cidadã em radioescola por parte de jovens estudantes do Ensino Fundamental na rede pública municipal de Fortaleza. O que se pretende não é sugerir um formato para a abordagem deste tipo de temática, mas socializar uma experiência de pesquisa dentro da qual o pesquisador não se exime de suas responsabilidades de cidadão.

\section{DESDE O INÍCIO: ELABORAÇÕES E REELABORAÇÕES DO DIÁRIO DE CAMPO}

A caminho de uma escola, o carro contorna o Castelão, maior estádio de futebol de Fortaleza, Ceará, e segue por ruas cada vez mais estreitas. Quanto maior a proximidade do destino, maior a percepção de que as casas que margeiam as ruas vão diminuindo em tamanho e se fundindo umas às outras. Do emaranhado de pequenas casas emergem um grande arco e um muro com pinturas que destacam aquele espaço de seu entorno: é a escola! Ao ultrapassar o portão de entrada, encontramos o pátio central vazio, pois está havendo aula. Em uma sala, uma placa na porta indica a "Rádio-escola". Ao entrarmos, percebemos que o lugar está empoeirado e é pouco utilizado. De acordo com a direção da escola, a rede elétrica do local não comporta o uso dos equipamentos ${ }^{3}$.

Voltando ao asfalto, destinamo-nos a uma segunda escola, localizada no Conjunto Palmeiras, desta vez contornando o desativado aterro de lixo do Jangurussu. Passamos por quatro portões para ter acesso a seu interior - cada um

2. MALDONADO, Alberto Efendy. A construção da cidadania científica como premissa de transformação sociocultural na contemporaneidade. In: Anais do XX Encontro da Compós. Disponível em: <http://www.compos. org.br>. Acesso em: 27 jun. 2011.

3. Reelaborações de diário de campo em visita à escola nos dias 5 e 6 de fevereiro de 2010.

4. Reelaborações de diário de campo em visita à escola no dia 26 de janeiro de 2010.

5. Reelaborações de diário de campo em visita à escola no dia 2 de outubro de 2009, ainda em fase exploratória da pesquisa. deles guardado por pessoas que controlam rigorosamente quem entra e quem sai da escola, em especial na hora do recreio,

Ao percorrermos o corredor, ouvimos músicas vindas do espaço da radioescola. Ao lado da música em baixo volume, que sai das caixas de som instaladas no corredor, também gritos, conversas, passos de corridas, pulos da brincadeira de elástico e sons da bolinha de pingue-pongue e da bola do futebol são outros elementos que compõem a paisagem sonora na hora do recreio ${ }^{4}$.

Seguimos em direção à terceira escola, na praia da Barra do Ceará, onde a entrada das pessoas parece ser menos controlada. Notamos intenso ir e vir de estudantes dentro e fora da escola. No canto do corredor há uma sala trancada por cadeado, cuja chave fica na direção. Nesse lugar estão os equipamentos de rádio.

Diferentemente das outras duas escolas, não há sinalização de que ali é uma radioescola. Nesse momento, a produção de programas foi interrompida e os equipamentos não estão sendo usados. Segundo a professora responsável, isto ocorre devido a problemas técnicos e, em especial, à transferência de muitos dos estudantes envolvidos com a rádio para escolas de Ensino Médio ${ }^{5}$.

Vamos, então, à quarta escola, localizada no bairro Bela Vista e mais próxima do Centro de Fortaleza. Ao chegarmos, uma das professoras nos chama 
apressadamente à sala da radioescola, que ocupa lugar de destaque no pátio central. O que se faz dentro da sala é visível, uma vez que sua grande janela de vidro é voltada para o pátio. A professora, que já havia gravado o programa com um grupo de estudantes, liga os equipamentos e veicula a gravação sobre frevo, trazendo informações e músicas que se misturam aos gritos e conversas do ambiente.

Sob olhares e ouvidos curiosos, o programa veiculado pela professora termina em cerca de dez minutos. É hora de começarem as aulas. Mais tarde, o som da sineta indicará o início do recreio. A mesma professora entra na sala para veicular outro programa, sobre forró. Novamente alguns estudantes dirigem-se à janela de vidro, onde podem ver o que está acontecendo na rádio. Começam a pedir músicas. Enquanto informações e músicas sonorizam a escola, meninas e meninos conversam, correm ou brincam ${ }^{6}$.

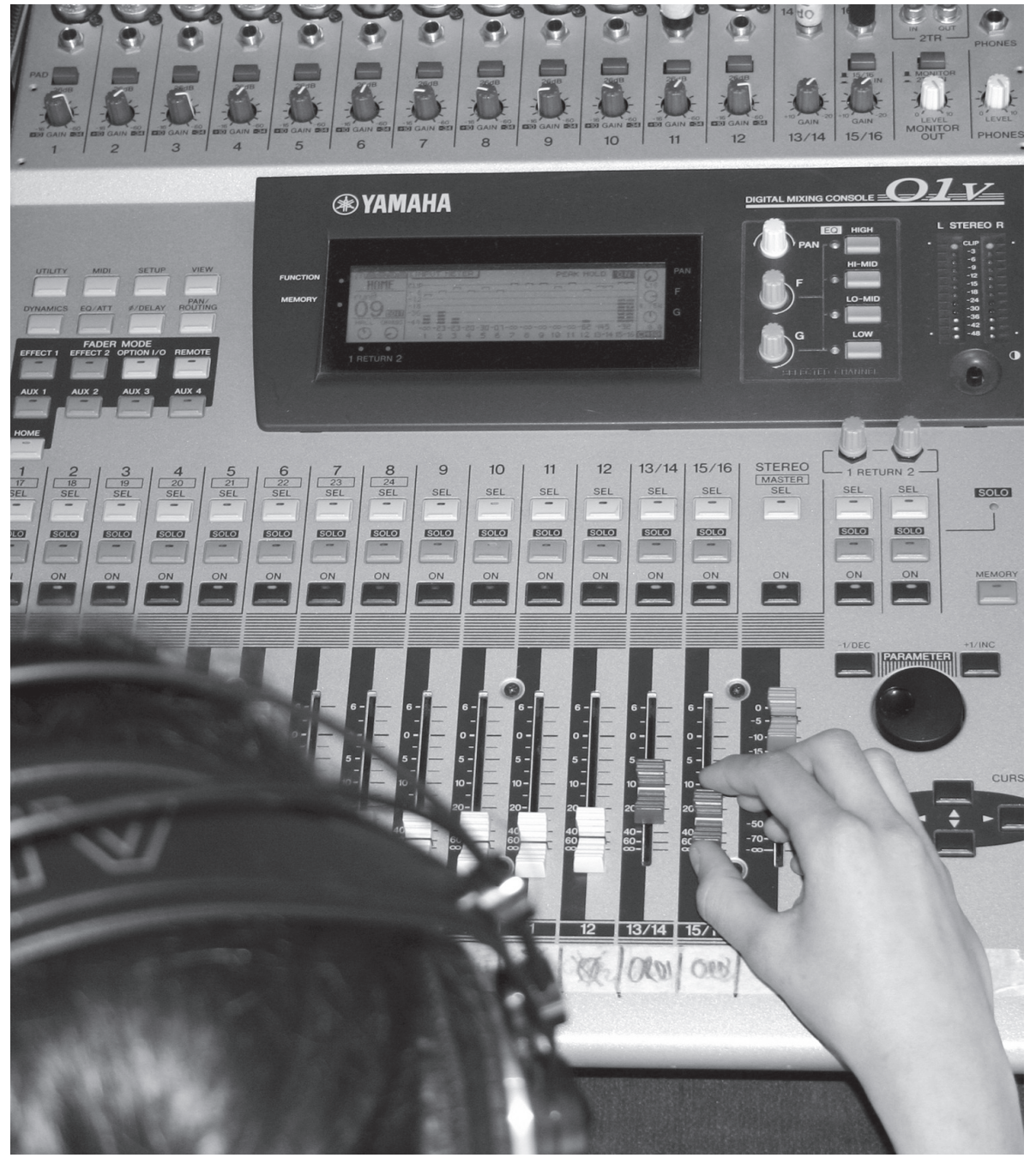

A pesquisa potencializou, entre outras, a discussão referente à seguinte questão: em que medida essas produções radiofônicas constituem exercícios para a cidadania?
6. Reelaborações de diário de campo em visita à escola nos dias 20 e 22 de janeiro de 2010 . 
comunicação \& educação • Ano XVII • número 2 • jul/dez 2012

As experiências de estudantes e professores nas quatro radioescolas citadas abriram a possibilidade de produção do programa Antenados, veiculado aos sábados entre os anos de 2008 e 2010, na Rádio Universitária FM, vinculada à Universidade Federal do Ceará. Além de envolver as escolas, o processo de produção e gravação do programa estendeu-se também ao espaço da ONG Catavento Comunicação e Educação, com sede em Fortaleza.

Para produzir os programas, uma equipe composta por uma pedagoga, uma jornalista e uma estagiária de Comunicação Social da ONG deslocava-se até as escolas para a realização de reuniões de pauta, em que eram definidos os temas específicos e o conteúdo de cada bloco. A cada semana a reunião ocorria em uma escola diferente, em esquema de rodízio. Após as reuniões, seguia-se a etapa de produção, quando os estudantes participantes realizavam pesquisas sobre os temas propostos - incluindo a gravação de entrevistas com a comunidade escolar ou no entorno da escola, além da escrita dos roteiros. O envolvimento de educadores no processo de produção variava de escola para escola, sendo mais intenso em algumas delas.

Quando concluídos, os roteiros eram revisados pela equipe da Catavento, que enviava sugestões às escolas. A revisão consistia na leitura do material por parte de profissionais das áreas da educação e da comunicação. A soma desses dois olhares durante a revisão objetiva potencializava a dimensão educativa dos processos de produção e dos conteúdos do Antenados, tanto entre os produtores como entre os futuros ouvintes dos programas.

Por fim, as principais alterações eram discutidas e avaliadas num encontro entre os grupos. Finalizada a revisão dos roteiros, realizava-se a gravação no estúdio da ONG. Gravadas as locuções e finalizada a edição, uma cópia do programa era, então, enviada à Rádio Universitária.

7. BARBALHO, Alexandre. Cidadania, minorias e mídia ou algumas questões postas ao liberalismo. In: BARBALHO, Alexandre; PAIVA, Raquel (org.) Comunicação e cultura das minorias. São Paulo: Paulus, 2005. p. 27-39.

\section{AS OPÇÕES TEÓRICO-METODOLÓGICAS}

Ocupando lugar de destaque nos espaços ou não, as radioescolas, bem como as cenas e os sons que se desenrolam junto a elas, foram os elementos que orientaram nosso olhar em visitas às quatro escolas.

A pesquisa que se seguiu teve como objetivo central analisar as experiências e práticas juvenis nos processos de produção, circulação de conteúdos e gestão de radioescolas na rede pública municipal de ensino da cidade de Fortaleza, tendo como perspectiva investigar os exercícios de cidadania que partiram desses processos. Como forma de estabelecer um recorte que tornasse viável a investigação, optamos por centrar a pesquisa de campo nas quatro escolas públicas que participaram do programa Antenados.

A pesquisa potencializou, entre outras, a discussão referente à seguinte questão: Em que medida essas produções radiofônicas constituem exercícios para a cidadania? $?^{7}$ Nosso pressuposto foi de que o acesso democrático aos meios de comunicação é elemento fundamental de afirmação cidadã para as minorias (nas quais se incluem os jovens), que dessa forma podem dar visibilidade a 
uma outra imagem sua que não a construída pela maioria. Nesse sentido, esta pesquisa permitiu a investigação das possibilidades e limitações das radioescolas e da rádio $\mathrm{FM}$ de se constituírem em espaços conquistados pelos estudantes para falarem de si e serem ouvidos.

Como metodologia apta à busca do objetivo proposto, escolheu-se a pesquisa participante. A crítica ao modelo segundo o qual "emissores transmitem mensagens aos receptores, que passivamente as decodificam”, além de encontrar respaldo teórico, também é desencadeada pela comunicação popular ou de base, que tem nos movimentos sociais seus principais sujeitos. Tal processo instaura discussões, no campo da comunicação, acerca das modalidades de pesquisa participante ${ }^{8}$.

Brandão, ao repensar a pesquisa participante, explica que a relação desigual entre mediador e comunidade jamais será extinta. Segundo o autor, partir do pressuposto de que a participação baseia-se em uma relação de igual poder e saber entre o "agente de mediação" e a "comunidade" esconde o fato de que há uma "desigualdade antecedente" que "não se resolve metodologicamente, nem na relação de compromisso entre os dois lados, nem, de modo específico, no interior de uma pesquisa participante" .

Se tais relações de desigualdade não se resolvem, como tentar, a partir do trabalho de pesquisa, viabilizar formas de resistência, mudanças ou mesmo solidariedade? Sobre essa questão, Brandão afirma que o papel do intelectual é o de ser "ouvinte" dos movimentos sociais, além de atuar como "um mediador que responde, com os instrumentos de seu saber e de sua profissão, a tais decisões e exigências, colocando-os a serviço não $d a$ comunidade, mas da prática política popular na comunidade"10.

Assim, na pesquisa participante, o processo de conhecimento está potencialmente interligado à prática política dos sujeitos e grupos com quem trabalhamos. Peruzzo, por exemplo, aponta a pesquisa participante como um tipo de investigação em que o pesquisador não apenas interage, mas desempenha papel cooperativo junto ao grupo pesquisado ${ }^{11}$.

Diante desse contexto, nossa preocupação se concentrou em aprofundar uma aproximação com os jovens não mais focada nas atividades de produção radiofônica, mas objetivando entender como aqueles sujeitos compreendiam e interpretavam o contexto da radioescola e da produção do programa Antenados.

Sobre a importância de compreender de que forma os sujeitos entendem o contexto, Paulo Freire afirma que "a realidade concreta é algo mais que fatos ou dados tomados mais ou menos em si mesmos. Ela é todos esses fatos e todos esses dados e mais a percepção que deles esteja tendo a população neles envolvida"12. Dessa forma, a pesquisa é marcada por um processo de aprendizado intenso por parte do pesquisador com os sujeitos com quem trabalha, ao passo que esses sujeitos também investigam, estudam e refletem.

Com relação aos procedimentos de pesquisa, optamos pela realização de rodas de conversa, comumente utilizadas nas práticas das ONGs. Segundo Abade e Afonso, a roda de conversa incentiva a participação e a reflexão ao "construir
8. COGO, Denise. Repensando a ciência participativa na pesquisa em comunicação. In: PAIVA, Raquel (org.). O retorno na comunidade: os novos caminhos do social. Rio de Janeiro: Mauad X, 2007. p. 149-166.

9. BRANDÃO, Carlos Rodrigues (org.). Repensando a pesquisa participante. São Paulo: Brasiliense, 1999.

10. Ibid., p. 251.

11. PERUZZO, Cicilia Maria Krohling. Da observação participante à pesquisa-ação em comunicação: pressupostos epistemológicos e metodológicos. In: CONGRESSO BRASILEIRO DE CIÊNCIAS DA COMUNICAÇÃO - INTERCOM, 26. Belo Horizonte: Intercom, 2003. p. 1-23.

12. FREIRE, Paulo. Criando métodos de pesquisa alternativa. In: BRANDÃO, Carlos Rodrigues (org.). Pesquisa participante. São Paulo: Brasiliense, 1983. p. 35. 
comunicação \& educação • Ano XVII • número 2 • jul/dez 2012

13. ABADE, Flávia Le mos; AFONSO, Lúcia. Para reinventar as rodas. Belo Horizonte: Rede de Cidadania Mateus Afonso Medeiros (Recivam), 2008 Disponível em: <http:// www.ufsj.edu.br/portal-repositorio/File/lapip/ para_reiventar_as_rodas. pdf>. Acesso em: 29 out. 2010. p. 19

14. MIRANDA, Luciana; SAMPAIO, Inês Silva Vitorino; LIMA, Tiago. Fazendo mídia, pensando educação: reverberações no mesmo canal. Comunicação \& Sociedade, Brasil, v. 30, n. 51, p. 89-112 jul. 2009. Disponível em: $<$ https://www.metodista. $\mathrm{br} /$ revistas/revistas-ims/ index.php/CSO/article/ view/855/906>. Acesso em: 6 mar. 2011. p. 103. condições para um diálogo entre os participantes através de uma postura de escuta e circulação da palavra, bem como com o uso de técnicas de dinamização de grupo" ${ }^{3}$. São, portanto, espaços que potencializam as discussões acerca do cotidiano, nas quais as narrativas intercalam-se tanto em torno da vida privada como da pública. Elas permitem, ainda, o percurso por uma linha de discussão de questões que partem das experiências do grupo. Também aspectos da subjetividade dos integrantes e da cultura imbricam-se nas rodas, uma vez que ali há "a possibilidade de criar entre os jovens um campo perceptivo onde cada um vê e é visto, sente e é sentido, sem hierarquias preestabelecidas" 14 .

Dessa forma, as rodas de conversa apresentaram-se como procedimento apropriado à pesquisa, por possibilitarem trocas de ideias entre nós e os grupos - mas, acima de tudo, por permitirem acompanhar as trocas entre os jovens. Nos encontros realizados, o incentivo à participação e à reflexão não partiu apenas da mediação, mas também das questões colocadas pelos sujeitos. Assim, elas se caracterizaram pela circulação da palavra, o que possibilitou a interpretação ou reinterpretação dos textos dos jovens numa perspectiva dialógica, envolvendo comunhão de ideias, fala e escuta.

Com duração média de uma hora, as rodas de conversa seguiram um roteiro de questões semiestruturadas. Para a completa aplicação deste roteiro, foram necessários dois encontros em cada uma das escolas, realizados entre outubro e dezembro de 2010. Portanto, mesmo levando em consideração a peculiaridade de cada grupo, repetimos a mesma estrutura de questões nas quatro escolas.

Ao final desse processo, participaram das rodas quinze estudantes que faziam parte das radioescolas ou da produção do programa Antenados. O número de sujeitos integrantes se mostrou adequado a uma escuta detalhada das falas, bem como ao desenvolvimento de uma investigação de acentuado cunho qualitativo.

Apesar da importância e potencialidade do roteiro em guiar as temáticas abordadas, cada roda precisou, de certa forma, ser "inventada": Como conversar com cada grupo? Como fazer dos encontros momentos interessantes e prazerosos para os jovens? Portanto, o desenvolvimento de cada roda possibilitou processos de aprendizado que permitiram a reavaliação e reformulação das questões e atividades propostas.

As primeiras questões elaboradas visaram à apresentação dos integrantes dos grupos. Nesse momento, as temáticas abordadas concentraram-se em dados pessoais, família e cotidiano. Os momentos finais, por sua vez, destinaram-se a relacionar as experiências de vida narradas, assim como os pensamentos do grupo sobre o tema "juventude". Percebemos que a possibilidade de falar de si mesmos despertou o interesse dos estudantes e os instigou a voltar nos encontros seguintes. Também as explicações sobre como seriam as rodas de conversa, sobre o que seria a pesquisa e sobre o que falaríamos satisfizeram a curiosidade inicial dos grupos e incentivaram seu envolvimento.

Como forma de estimular a participação e aumentar nossa compreensão sobre a temática juventude, formulamos uma atividade que deveria ser desenvolvida no intervalo entre a primeira e a segunda roda de conversa. Como a maioria 
dos estudantes afirmara reconhecer-se como jovem, pedimos que trouxessem ao segundo encontro algo que afirmasse sua juventude. $\mathrm{O}$ compartilhamento do que foi trazido por cada um dos integrantes deu início às segundas rodas de conversa, quando promovemos também a discussão acerca das temáticas cidadania, cotidiano escolar e radioescola.

As rodas de conversa objetivaram saber como se deu a formação do grupo de estudantes para a produção radiofônica, qual a dinâmica das atividades desenvolvidas durante as produções dos programas de rádio - desde a definição do tema do programa até os momentos de gravação e edição -, além de quais os interesses dos estudantes durante o processo de produção para o rádio. Os depoimentos foram gravados, o que possibilitou um fiel aproveitamento das citações relevantes para a investigação. Por fim, concluídas oito rodas de conversa, marcamos um terceiro encontro em cada uma das escolas, visando à realização de uma escuta coletiva do programa Antenados.

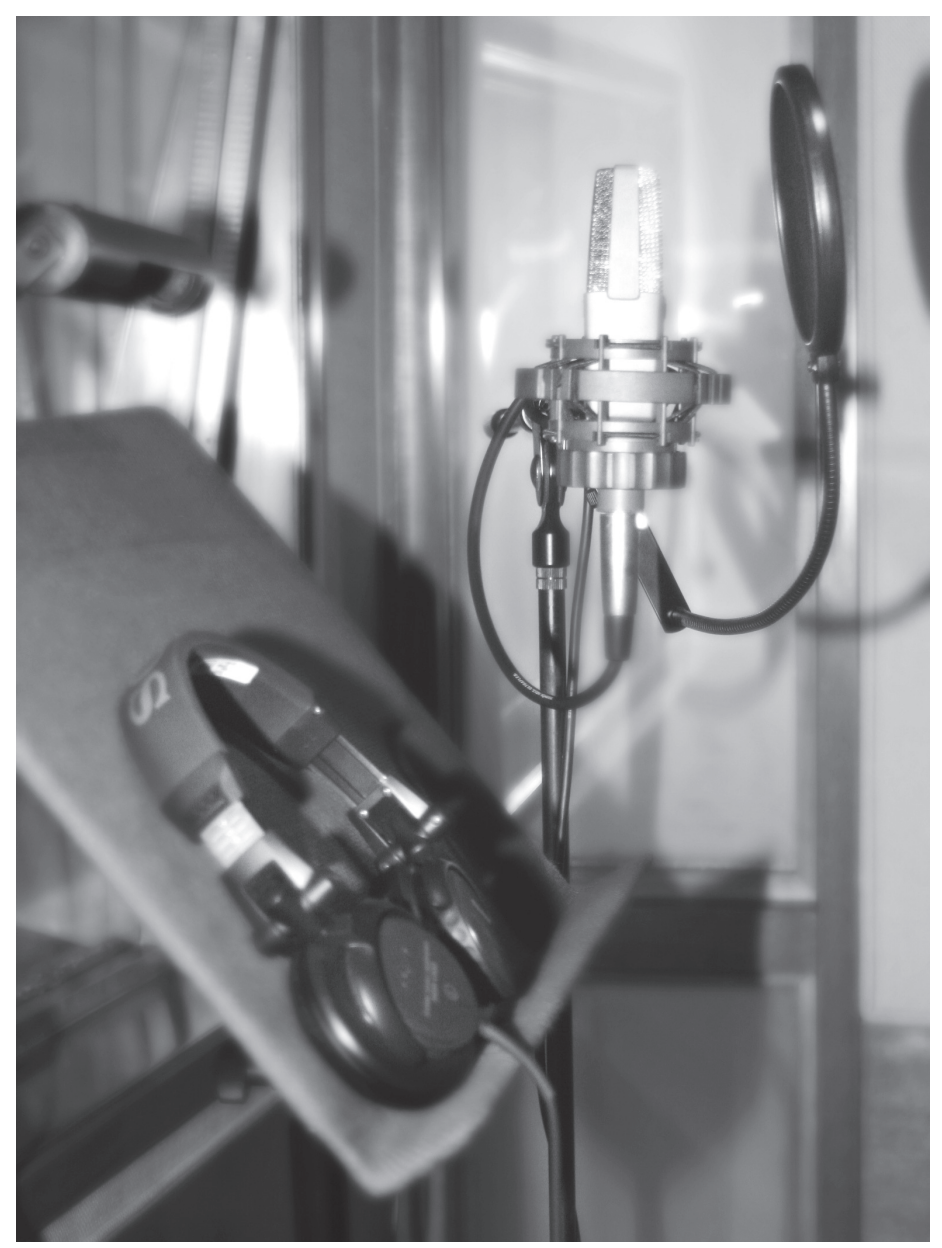

O pressuposto da pesquisa foi de que o acesso democrático aos meios de comunicação é elemento fundamental de afirmação cidadã para as minorias. 
comunicação \& educação • Ano XVII • número 2 • jul/dez 2012

\section{CONSIDERAÇÕES FINAIS}

A perspectiva de observação, proveniente de pesquisa de cunho etnográfico nas escolas, possibilitou a compreensão e a análise dos produtos radiofônicos em si, primando pela dimensão processual. A pesquisa nesses cenários foi guiada pela observação do cotidiano, na qual se busca analisar os processos de construção de sentido na perspectiva dos próprios sujeitos.

Assim, importa considerar as práticas vivenciadas pelos jovens como forma de melhor compreender o significado de sua fala. Para melhor percebê-las, realizamos entrevistas e conversas com os demais sujeitos envolvidos com as radioescolas, tais como professores, diretores e ex-participantes.

A pesquisa, portanto, apresentou o acompanhamento de práticas e experiências juvenis em processos de produção e circulação de conteúdos, bem como de gestão de radioescolas em quatro instituições de ensino público municipal. Os dados apresentados com base na empiria, articulados com estudos teóricos que abordam a relação entre juventude, cidadania e comunicação, confirmaram a importância da ênfase na escuta das percepções dos jovens sobre os processos vivenciados, principalmente na análise de projetos e ações realizados por instituições voltadas a eles.

A pesquisa partiu da compreensão de que os processos comunicacionais são formados por sujeitos interlocutores em meio à complexidade de discursos, contextos sociais e culturais. Tais processos são marcados ainda por negociações e conflitos. Vimos que essa perspectiva teórica traz repercussões nos modos de fazer ciência em comunicação, influenciando, portanto, as metodologias científicas. Assim fundamentados, optamos pela pesquisa participante como norteadora dos percursos deste estudo nos espaços sociais. A realização de rodas de conversa foi a técnica desenvolvida como forma de obter os relatos dos estudantes.

Percebemos que a técnica das rodas de conversa, pensada juntamente com atividades que estimulassem a participação e o ânimo dos estudantes, possibilitou o desvelar de relatos extremamente relevantes para avaliações das práticas propostas. Com delicadeza, os jovens expuseram tanto os pontos que consideraram favoráveis como as críticas aos processos de produção. Acreditamos que a escuta exclusiva de grupos de estudantes favoreceu tal aspecto dos relatos. A pesquisa possibilitou, portanto, a valorização dessas falas.

\section{REFERÊNCIAS BIBLIOGRÁFICAS}

ABADE, Flávia Lemos; AFONSO, Lúcia. Para reinventar as rodas. Belo Horizonte: Rede de Cidadania Mateus Afonso Medeiros (Recivam), 2008. Disponível em: <http:/ / www.ufsj.edu.br/portal-repositorio/File/lapip/para_reiventar_as_rodas.pdf $>$.

BARBALHO, Alexandre. Cidadania, minorias e mídia ou Algumas questões postas ao liberalismo. In: BARBALHO, Alexandre; PAIVA, Raquel (org.). Comunicação e cultura das minorias. São Paulo: Paulus, 2005. 
; COGO, Denise; FUSER, Bruno. Comunicação para a cidadania: um breve panorama das tendências de pesquisa a partir da Intercom. In: VICENTE, Maximiliano Martin; ROTHBERG, Danilo (org.). Meios de comunicação e cidadania. São Paulo: Cultura Acadêmica, 2010.

BRANDÃO, Carlos Rodrigues (org.). Repensando a pesquisa participante. São Paulo: Brasiliense, 1999.

COGO, Denise. Repensando a ciência participativa na pesquisa em comunicação. In: PAIVA, Raquel (org.). O retorno na comunidade: os novos caminhos do social. Rio de Janeiro: Mauad X, 2007.

FREIRE, Paulo. Criando métodos de pesquisa alternativa. In: BRANDÃO, Carlos Rodrigues (org.). Pesquisa participante. São Paulo: Brasiliense, 1983.

MALDONADO, Alberto Efendy. A construção da cidadania científica como premissa de transformação sociocultural na contemporaneidade. In: Anais do XX Encontro da Compós. Disponível em: <http://www.compos.org.br >. Acesso em: 27 jun. 2011.

MIRANDA, Luciana; SAMPAIO, Inês Silvia Vitorino; LIMA, Tiago. Fazendo mídia, pensando educação: reverberações no mesmo canal. Comunicação \& Sociedade, Brasil, v. 30, n. 51, p. 89-112, jul. 2009. Disponível em: <https://www.metodista. $\mathrm{br} /$ revistas/revistas-ims/index.php/CSO/article/view/855/906>.

PERUZZO, Cicilia Maria Krohling. Da observação participante à pesquisa-ação em comunicação: pressupostos epistemológicos e metodológicos. In: CONGRESSO BRASILEIRO DE CIÊNCIAS DA COMUNICAÇÃO - INTERCOM. Belo Horizonte: Intercom, 2003. p. 1-23. 


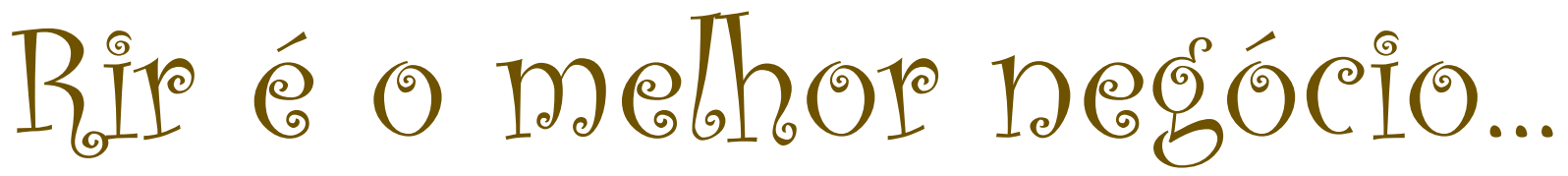

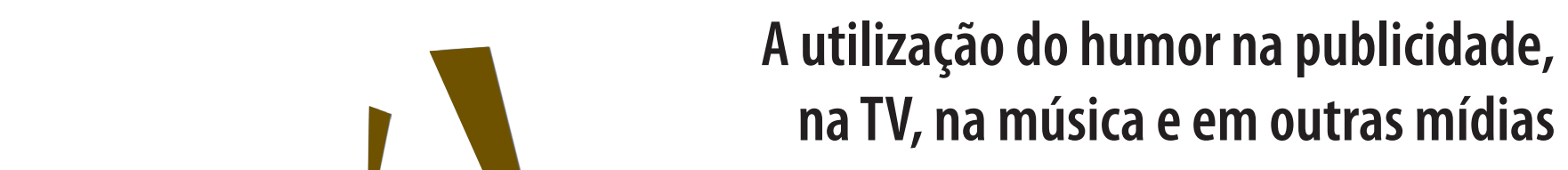

Sempre escutamos que rir é o melhor remédio. Aliás, esse ditado já é cientificamente comprovado. Rir faz bem à alma. É realmente impossível uma pessoa não se sentir bem depois de uma sessão

de gargalhadas. Partindo dessa premissa, muitos autores, produtores e profissionais de marketing utilizam o humor em seus negócios.

0 humor hoje se tornou uma fórmula de sucesso na TV, na publicidade, na música e até mesmo no jeito de dar as notícias. Esse gênero é utilizado para atrair o público e, posteriormente, promover a aceitação de produtos e marcas.

Este livro apresenta estudos sobre esse fenômeno nos meios de comunicação. 0 objetivo dos autores é aprofundar a discussão sobre 0 tema de uma maneira abrangente e analítica. Leitura imprescindível para os interessados no humor em geral, pesquisadores de histórias em quadrinhos, TV, cinema, rádio e outros veículos de comunicação, afinal, o humor está presente em todas as mídias.

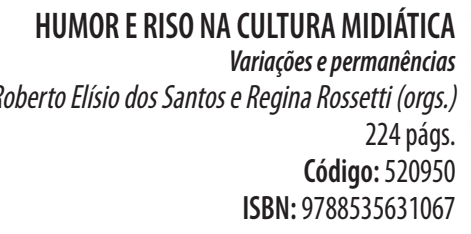

